\title{
VALUASI EKONOMI JASA LINGKUNGAN EKOSISTEM HUTAN TAMAN EDEN 100, DESA LUMBAN JULU, PARAPAT, SUMATERA UTARA
}

\author{
Ivany Gresya Saragih ${ }^{1 *}$, Made Sudiana Mahendra ${ }^{2)}$, I Made Sudarma ${ }^{2)}$ \\ ${ }^{1)}$ Program Studi Magister Ilmu Lingkungan Universitas Udayana Bali \\ ${ }^{2}$ Pascasarjana Doktor Ilmu Lingkungan Universitas Udayana Bali \\ ${ }^{2}$ Pascasarjana Doktor Ilmu Lingkungan Universitas Udayana Bali \\ *Email: ivanyyy@ymail.com
}

\section{ABSTRACT \\ ECONOMIC VALUATION ON ENVIRONMENTAL SERVICES OF EDEN 100 FOREST PARK ECOSYSTEM IN PARAPAT, NORTH SUMATRA}

Eden 100 Forest Park in the village of Lumban Julu is an ecotourism area that has a potential for natural resources that can be used as a tourist attraction. Not only is the potential of natural resources in the form of tourist items provided by Taman Eden 100 forest tourism, but there are many other environmental services provided by the Eden Park 100 tourist forest. This study aims to determine which environmental services are provided by Taman Eden 100 forest tourism and analyze the economic value of environmental services, as well as the obstacles and challenges faced by managers to preserve forest ecosystems. The results showed that the Taman Eden 100 tourism forest provides environmental services in the form of direct use of environmental services, namely production of wood and non-timber products (fruits), indirect use services in the form of natural landscapes can be used as ecotourism, services not related to services such as carbon sinks. The four services were evaluated to obtain the total economic value of the Eden Forest 100 tourist forest. The economic value of production of wood and nonwood products was calculated using market value and the results were obtained, namely the

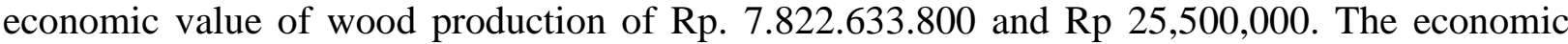
value of ecotourism is calculated using the Travel Cost Method (TCM). The results obtained are $\mathrm{Rp} 1,164,181,800$. The economic value of existence is calculated using the contingent valuation

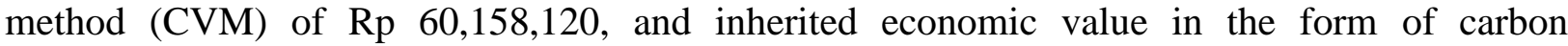

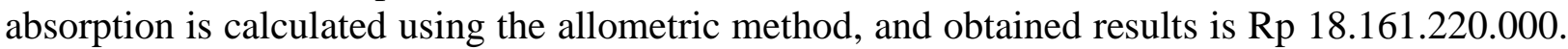
The results of this study, it can be concluded that the existence of the Taman Eden 100 tourism forest provides great economic benefits if its sustainability continues to be maintained because it can absorb carbon which provides a large economic value about $\mathrm{Rp} 27.233 .693 .720$

Keywords: Environtmental services, Economic Valuation, Tourism Forest

\section{PENDAHULUAN}

Hutan sebagai salah satu sumber daya alam terbaharukan, memiliki peran penting dalam menopang kehidupan manusia, tempat berkembangbiak flora dan fauna serta organisme lain. Hutan juga menyediakan barang dan jasa, baik berupa manfaat langsung seperti kayu dan hasil hutan bukan kayu, maupun tidak langsung seperti jasa lingkungan yang dalam pemanfaatannya dimanfaatkan untuk kepentingan ekonomi, sosial-budaya, dan perlindungan ekologis.

Nilai suatu kawasan hutan sering kali dihitung hanya berdasarkan nilai jumlah produksi kayu yang dihasilkan hutan, padahal hutan juga mempunyai nilai manfaat jasa lingkungan yang kadang kala nilainya lebih besar dari nilai produksi kayu. Jasa lingkungan hutan yang masih sering terabaikan dapat menyebabkan meningkatnya laju degradasi ekosistem hutan. Sejumlah jasa lingkungan lain yang dihasilkan dari hutan 
yaitu jasa lingkungan air, jasa penyimpanan karbon (carbon stock), penyedia wisata alam serta tempat keanekaragaman hayati.

Menurut Darusman (2006) dalam Heriyanto dan Endro (2016), jasa hutan dalam penyerapan dan penyimpanan karbon guna mengurangi $\mathrm{CO}_{2}$ di udara mencapai $77,9 \%$, sedangkan manfaat langsung dari pengolahan hutan berupa hasil kayu hanya $4,1 \%$.

Jasa lingkungan lain yang disediakan oleh hutan adalah menyediakan keindahan bentang alam. Ekowisata merupakan salah satu bentuk penyediaan jasa lingkungan berupa keindahan bentang alam dan merupakan kebijaksanaan pembangunan di bidang kehutanan yang didasarkan atas asas manfaat dan lestari serta konservasi sumber daya alam hayati dan ekosistemnya. Namun, pada perkembangannya industri pariwisata kerap kali merusak lingkungan dan mengabaikan kelestarian lingkungan. Jika nilai kerusakan lingkungan ini terus menerus diabaikan oleh pelaku ekonomi, maka dapat mengakibatkan kerusakan lingkungan secara terus menerus.

Hutan wisata Taman Eden 100 merupakan hutan kawasan ekowisata yang masih berada di kawasan Danau Toba. Hutan ini masuk dalam Kawasan Pengelolaan Hutan Lindung (KPHL) Model Unit XIV Toba Samosir. Kawasan Hutan di KPHL Tobasa ini memiliki peran sebagai hulu DAS Asahan yang memegang peranan penting bagi masyarakat sekitarnya. Tak hanya itu hutan ini merupakan daerah hilir dari sub DAS Naborsahon, dimana sub DAS Naborsahon ini berada dalam daerah tangkapan air (DTA) Danau Toba. Hutan Taman Eden 100 merupakan hutan kawasan ekowisata yang masih berada di kawasan Danau Toba. Hutan yang dikelola oleh perorangan ini mempunyai luas sekitar \pm 40 Hektar dengan potensi obyek daya tarik wisata alam berupa hutan alami, dengan pohon pohon yang menjulang tinggi, baik pohon buah buahan maupun pohon yang termasuk dengan tanaman langka. Tidak hanya memproduksi hasil hutan seperti buah buahan, dan penyedia keindahan bentang alam, hutan Taman Eden 100 ini juga berkontribusi dalam menyediakan jasa lingkungan berupa penyerapan karbon lewat vegetasi yang ada di hutan Taman Eden.
Ketersediaan dan pemanfaatan barang dan jasa lingkungan Hutan Taman Eden 100 ini sangat berpengaruh terhadap kegiatan ekonomi, keberlanjutan lingkungan dan kesejahteraan masyarakat sekitar. Barang dan jasa yang dihasilkan ekosistem hutan baik hasil hutan berupa buah-buahan, penyedia keindahan bentang alam, dan juga penyerapan karbon sangat penting di valuasi untuk pembangunan yang berkelanjutan. Oleh karena itu diperlukannya suatu valuasi jasa lingkungan untuk memberi nilai (value) terhadap jasa lingkungan ekosistem hutan terhadap hutan Taman Eden 100.

\section{METODOLOGI}

\subsection{Lokasi dan Waktu Penelitian}

Penelitian ini dilakukan di Dusun Lumban Rang, Desa Sionggang Utara, Kecamatan Lumban Julu, Kabupaten Toba Samosir, Sumatera Utara yang dilakukan selama 3 bulan dari bulan Januari 2019 hingga Maret 2019. Pemilihan lokasi penelitian ditentukan secara sengaja (purposive) dengan pertimbangan bahwa obyek wisata tersebut merupakan daerah kawasan hutan ekowisata yang sering dijadikan sebagai sarana penelitian, pendidikan dan rekreasi. Kawasan ini masih termasuk dalam kawasan pariwisata Danau Toba, dan merupakan kawasan wisata favorit di Sumatera Utara.

Menurut data dari BKSDA 1 Sumut (2003), hutan wisata Taman Eden 100 berbatasan dengan:

Sebelah Utara : Kecamatan AJibata Kabupaten Simalungun

Sebelah Selatan : Kecamatan Uluan, Kecamatan Porsea Kabupaten Toba Samosir

Sebelah Barat : Danau Toba, Kecamatan Ajibata Kabupaten Simalungun.

Sebelah Timur : Kecamatan Asahan. (Sumber : BKSDA 1 Sumut, 2003) 


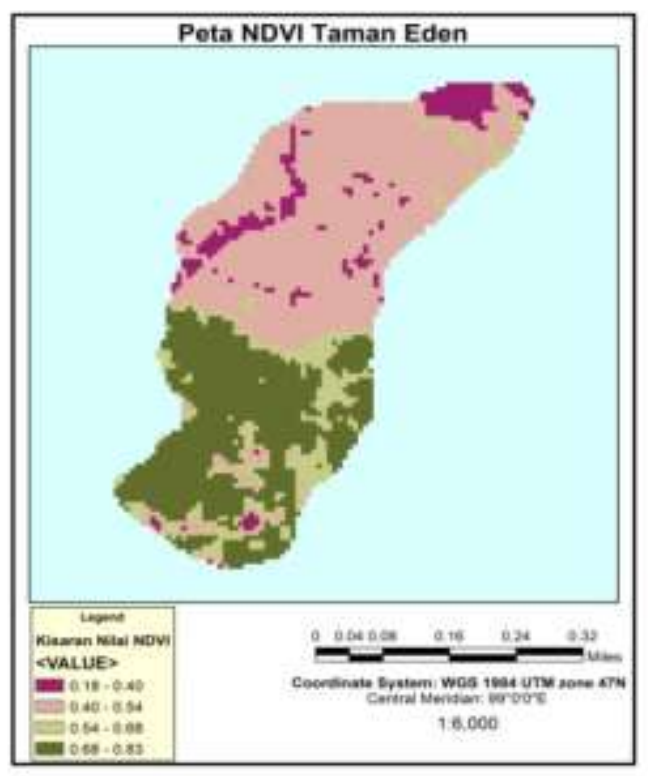

Gambar 1.

Peta Lokasi Taman Eden 100 (Sumber : Peta NDVI)

\subsection{Prosedur Penelitian}

Untuk mengetahui valuasi ekonomi jasa ekosistem Hutan Taman Eden 100, maka diperlukan beberapa rancangan penelitian terkait jasa ekosistem yang disediakan hutan wisata Taman Eden 100. Rancangan penelitian yang akan dilakukan di lapangan yaitu jasa penghasil kayu dan non kayu. Hal ini berkaitan dengan diameter pohon untuk mengetahui volume pohon yang nantinya akan dihitung berdasarkan nilai pasar. Hal yang serupa juga dilakukan untuk mengetahui nilai ekonomi non kayu (buah-buahan), dengan menghitung banyaknya buah yang dihasilkan dikali dengan harga pasar. Terkait dengan jasa dalam menyediakan keindahan bentang alam sebagai non dirrect use value, perlunya dilakukan penelitian terhadap wisatawan dengan cara melakukan wawancara dengan menggunakan beberapa pertanyaan yang sudah ada di dalam kuesioner yang bertujuan untuk mengetahui biaya perjalanan.

Jasa ekosistem hutan lainnya yaitu dalam penyerapan karbon dimulai dengan mengidentifikasi lokasi yang akan di jadikan sampel penelitian jasa lingkungan penyerapan karbon. Setelah mengidentifikasi lokasi yang akan dijadikan sampel penelitian, maka selanjutnya, akan mengukur diameter pohon. Data yang telah diperoleh selanjutnya akan diolah sehingga adanya pendugaan biomassa yang tersimpan. Biomassa yang tersimpan selanjutnya akan dikonversikan sehingga menghasilkan dugaan nilai ekonomi penyerapan karbon oleh hutan wisata Taman Eden 100.

Jasa ekosistem hutan lainnya yang teridentifikasi adalah jasa keberadaan sebagai non use value. Jasa ini dapat divaluasi dengan menggunakan contingent valuation method. Untuk itu perlu dilakukannya penelitian terhadap kesediaan wisatawan dalam membayar jasa daam pelestarian lingkungan.

\subsection{Analisis Data}

Analisis data dalam penelitian ini menggunakan analisis deskriptif dan analisis kuantitatif. Analisis deskriptif lebih mendeskripsikan data karakteristik wisatawan dan persepsi pengunjung Hutan Wisata Taman Eden 100. Data karakteristik ini mengenai profil responden menurut aktivitas wisatawan, gender, umur, asal, pendapatan, pendidikan, situs pekerjaan, jarak tempuh, waktu tempuh, dan biaya perjalanan. Analisis Kuantitatif dalam penelitian ini adalah dihitung dengan menggunakan nilai ekonomi kawasan Hutan Wisata Taman Eden 100. Nilai ekonomi Hutan Wisata Taman Eden 100 ini meliputi nilai guna (use value), nilai non guna (non use value). Nilai guna ini terdiri dari nilai penggunaan langsung (direct use value) seperti nilai ekonomi produksi kayu dan non kayu yang dihitung dengan nilai harga pasar, sedangkan nilai penggunaan tidak langsung (non use value) yang terdiri dari nilai penyedia bentang alam (ekowisata) yang dihitung dengan travel cost. Nilai non guna terdiri dari nilai keberadaan yang dihitung dengan pendekatan CVM (Contingent Valuation Method), dan nilai warisan berupa nilai penyerapan karbon.

\subsection{Variabel Penelitian}

Berkaitan dengan data yang akan dikumpulkan dalam penelitian ini, maka terdapat beberapa variabel yang diamati adalah:

1. Diameter pohon diperlukan untuk mengetahui rata rata kemampuan pohon dalam penyerapan karbon, 
dengan terlebih dahulu mengetahui keliling dan tinggi pohon.

2. Biaya perjalanan adalah: biaya yang dikeluarkan wisatawan seperti: tiket pesawat, tiket bus, sewa mobil atau bensin, dan biaya makan.

3. Sosial ekonomi seperti pendapatan, pekerjaan dan pendidikan yang mempengaruhi kunjungan Hutan Wisata Taman Eden 100.

4. Demografi seperti agama, umur, jenis kelamin, status perkawinan, dan daerah asal yang mempengaruhi kunjungan ke Hutan Wisata Taman Eden 100.

5. Nilai nominal rata-rata kesediaan membayar untuk membayar konservasi Hutan Wisata Taman Eden 100 yang bersedia dibayarkan oleh wisatawan per kunjungan.

\subsection{Instrumen Penelitian}

Penelitian terhadap Hutan Wisata Taman Eden 100 sebagai obyek wisata, akan menggunakan data yang digali dari wisatawan (responden) dengan menggunakan kuesioner. Kuesioner akan disebar kepada wisatawan pada pos pembayaran tiket. Alat yang digunakan dalam penelitian ini adalah alat tulis, GPS, meteran, pita merah, clinometer, kuesioner, Google Earth dan peta NDVI yang berfungsi untuk memetakan lokasi penelitian, laptop serta kamera untuk dokumentasi.

\subsection{Analisis Data}

\subsubsection{Analisis deskriptif}

Analisis ini lebih mendeskripsikan data karakteristik wisatawan dan persepsi pengunjung Hutan Wisata Taman Eden 100. Data karakteristik ini mengenai profil responden menurut gender, umur, asal, pendapatan, pendidikan, status pekerjaan, jarak tempuh, waktu tempuh, dan biaya perjalanan. Penjelasan secara deskriptif juga diperlukan dalam mengetahui kendala serta hambatan apa saja yang dihadapi oleh pengelola dalam mengelola jasa lingkungan hutan wisata Taman Eden 100 untuk mewujudkan ekowisata yang berkelanjutan.

\subsubsection{Analisis kuantitatif}

Analisis Kuantitatif dalam penelitian ini adalah dengan valuasi jasa lingkungan yang ditawarkan oleh Hutan Taman Eden 100 yang dihitung dengan menggunakan nilai ekonomi kawasan Hutan Wisata Taman Eden 100. Nilai ekonomi Hutan Wisata Taman Eden 100 ini meliputi nilai guna (use value), nilai non guna (non use value). Nilai guna ini terdiri dari nilai penggunaan langsung (direct use value) seperti nilai ekonomi produksi kayu, nilai ekonomi buah-buahan, sedangkan nilai penggunaan tidak langsung (non use value) yang terdiri dari nilai penyedia bentang alam yang dihitung dengan Travel cost dan nilai penyerapan karbon. Nilai non guna terdiri dari nilai keberadaan yang dihitung dengan pendekatan CVM (Contingent Valuation Method). Menurut Munasinghe, 1993 dalam Sumarno, 2010 persamaan total nilai ekonomi dijabarkan dalam persamaan berikut:

$$
\mathrm{TEV}=\mathrm{UV}+\mathrm{NUV}
$$

Dimana:

$\mathrm{TEV}=$ Total Economic Value atau nilai ekonomi total (dalam Rupiah).

$\mathrm{UV}=$ Use Value atau nilai penggunaan langsung (dalam Rupiah).

$\mathrm{NUV}=$ Non Use Value atau nilai tanpa penggunaaan (dalam Rupiah).

\section{HASIL DAN PEMBAHASAN}

\subsection{Gambaran Umum daerah Penelitian}

Hutan Taman Eden 100 merupakan kawasan Hutan Alam yang terletak di Dusun Lumban Rang, Desa Sionggang Utara, Kecamatan Lumban Julu, Kabupaten Toba Samosir, Parapat, Sumatera Utara.. Hutan ini masuk dalam Kawasan Pengelolaan Hutan Lindung (KPHL) Model Unit XIV Toba Samosir. Kawasan Hutan Taman Eden 100 merupakan hutan lindung yang masih alami dengan luas \pm 40 ha. Hutan Taman Eden 100 menyediakan kegiatan ekowisata seperti 
aktivitas camping ground, tracking dan juga penelitian vegetasi anggrek serta birding, selain itu di hutan wisata Taman Eden 100 juga terdapat air terjun 2 tingkat, bukit manja, gunung pangulubao, kebun pembibitan, kebun andaliman. Untuk dapat menikmati keindahan alam Hutan Taman Eden, pengunjung cukup membayar tiket masuk sebesar Rp 5.000 per orang untuk wisatawan domestik, dan Rp 10.000 untuk wisatawan mancanegara.

\subsection{Karakteristik Wisatawan}

Dalam menghitung nilai ekonomi hutan wisata Taman Eden 100 dalam penyedia bentang alam (ekowisata) yang dihitung menggunakan travel cost, maka diperlukan data karakteristik wisatawan melalui kuesioner yang dibagikan kepada 50 orang wisatawan. Data karakteristik wisatawan tersebut berupa aktivitas wisatawan dengan aktivitas terbanyak bertujuan untuk melakukan tracking, tingkat pendapatan terbanyak sekitar Rp 3.000.000 $\mathrm{Rp}$ 4.000.000, status pekerjaan terbanyak yaitu non PNS, status pendidikan terbanyak yaitu non sarjana, jenis kelamin terbanyak yaitu pria, status pernikahan terbanyak belum menikah, dan pengunjung terbanyak berumur sekitar 15-25 tahun, serta daerah asal pengunjung terbanyak berasal dari Provinsi Sumut.

\subsection{Valuasi Ekonomi Hutan Wisata Taman Eden 100}

\subsubsection{Nilai Ekonomi Kayu dan Non Kayu}

Jasa lingkungan yang diberikan Hutan Wisata Taman Eden memiliki nilai penggunaan langsung yaitu berupa produksi hasil hutan kayu dan non kayu. Jasa lingkungan Hutan Wisata Taman Eden dalam hasil produksi hutan hanya sebatas non kayu saja. Namun, nilai penggunaan langsung berupa produksi kayu ini dapat diukur dengan mengestimasikan nilai ekonomi kayu yang dimiliki oleh hutan Wisata Taman Eden 100. Nilai ekonomi pohon dihitung dengan konsep harga pasar yaitu perhitungan menurut Husch B et al., (2003)

$$
\mathrm{NK}=\mathrm{VK} \times \mathrm{H}
$$

Keterangan :

NK = Nilai Manfaat Kayu $\left(\mathrm{Rp} / \mathrm{m}^{3}\right)$

$\mathrm{H} \quad=$ Harga Pasar (Rp)

$\mathrm{VK}=$ Volume Kayu $\left(\mathrm{m}^{3}\right)$

Menurut .Menteri Lingkungan Hidup Dan Kehutanan Republik Indonesia Nomor: P.64/Menlhk/Setjen/Kum.1/12/2017 Tentang: Penetapan Harga Patokan Hasil Hutan Untuk Perhitungan Provisi Sumber Daya Hutan Dan Ganti Rugi Tegakan, harga Kayu berdasarkan ciri kayu bulat dari hutan alam yang berasal dari wilayah Sumatera dengan ukuran Kayu Bulat Besar (KBB) adalah seharga Rp 690.000 per $\mathrm{m}^{3}$.

Dalam menghitung volume kayu, terlebih dahulu diukur lingkar pohon , kemudian dihitung diameter nya. Pohon yang diukur merupakan pohon di tiap plot yang sudah ditandai seluas $20 \mathrm{~m}$ x $20 \mathrm{~m}$. Sample yang digunakan menggunakan 5 plot yang tiap plot terdiri dari 10 pohon dengan diameter $>35 \mathrm{~cm}$, dengan tinggi rata-rata pohon yang hampir seragam yang diambil dari 5 plot di daerah penelitian, yang dianggap mampu mewakili keseluruhan lokasi penelitian. Rumus yang digunakan untuk menghitung Volume pohon adalah :

$$
\mathrm{V}=1 / 4 \times \pi \mathrm{xd}^{2} \times \mathrm{t}
$$

Keterangan:

$\mathrm{V} \quad=$ Volume Pohon

$\pi \quad=$ phi (3.14)

$\mathrm{d}=$ diameter

$\mathrm{t} \quad=$ tinggi pohon

Tabel 1. Nilai Manfaat Ekonomi Kayu Hutan Wisata Taman Eden 100

\begin{tabular}{rcc}
\hline $\begin{array}{l}\text { No } \\
\text { Plot }\end{array}$ & $\begin{array}{c}\text { Total Volume } \\
\text { Plot }(\mathbf{m 3})\end{array}$ & $\begin{array}{c}\text { Nilai Kayu } \\
(\mathbf{R p} / \mathbf{m 3})\end{array}$ \\
\hline $\mathbf{1}$ & 16,03 & 6.253 .528 \\
\hline $\mathbf{2}$ & 18,18 & 7.093 .914 \\
\hline $\mathbf{3}$ & 22,08 & 8.611 .632 \\
\hline $\mathbf{4}$ & 20,54 & 8.013 .898 \\
\hline $\mathbf{5}$ & 23,43 & 9.139 .197 \\
\hline & Total & 39.112 .169 \\
\hline
\end{tabular}




$$
\begin{aligned}
\text { Nilai Ekonomi Total } & =\frac{40 \mathrm{Ha}}{0,2 \mathrm{Ha}} \times 39.112 .169 \\
& =\operatorname{Rp} 7.822 .633 .800
\end{aligned}
$$

Maka dapat disimpulkan, estimasi nilai ekonomi total kayu hutan Taman Eden seluas $40 \mathrm{Ha}$ mempunyai nilai sebesar $\mathrm{Rp}$ 7.822.633.800.

Nilai non kayu yaitu buah-buahan yang di berikan oleh hutan wisata Taman Eden 100 dapat dihitung juga dengan harga pasar. Berdasarkan informasi yang diperoleh dari pengelola, pohon jeruk panen bisa sekitar 2 kali dalam setahun dengan jumlah pohon sekitar 25 pohon jeruk dan untuk satu pohon jeruk bisa menghasilkan 20 kilogram jeruk, sedangkan untuk tanaman stroberi dalam setahun dapat menghasilkan keuntungan sebesar Rp 15.000.000 dengan biaya pemeliharaan sebesar 4.500.000. Maka total nilai ekonomi produksi hasil non kayu (buahbuahan) dapat dihitung sebagai berikut:

Nilai Ekonomi Total $=($ HJjeruk $\quad+$ Hjstroberi) - Biaya Operasional

$=((500 \mathrm{~kg} \quad \mathrm{x} \quad \mathrm{Rp} 15.000 \quad \mathrm{x} \quad 2 \quad \mathrm{kali}) \quad+$ $15.000 .000)-4.500 .000$

$=(15.000 .000+15.000 .000)-4.500 .000$

$=25.500 .000$.

Dari perhitungan tersebut, diperoleh hasil estimasi nilai ekonomi non kayu (buahbuahan) sebesar Rp 25.500.000, yang artinya hutan Taman Eden 100 memiliki manfaat ekonomi dalam produksi hasil hutan non kayu sebesar Rp 25.500.000.

\subsubsection{Nilai Ekonomi Sebagai Penyedia Bentang Alam (Wisata Alam)}

Hutan Wisata Taman Eden menawarkan jasa lingkungan sebagai wisata alam, maka perlu dilakukan perhitungan nilai ekonomi yang menggunakan pendekatan travel cost. Nilai ekonomi dengan menggunakan pendekatan travel cost akan mengacu pada rumus Grandstaff and Dixon (1991) dalam Ketut Suja (2007) sebagai berikut:

$$
\mathrm{TTC}=\sum_{i=1}^{50} A T C i\left[\begin{array}{c}
n i \\
N
\end{array}\right] T
$$

Keterangan :

TTC = Total Travel Cost (dalam Rupiah)
ATCi = Average Travel Cost atau rata rata biaya perjalanan pergi pulang (dalam Rupiah), jumlah wisatawan 1 sampai 50.

ni = banyaknya responden yang bersedia membayar AWPi dan atau mengeluarkan biaya perjalanan pergi pulang.

$\mathrm{N}=$ banyaknya responden yang mengisi kuesioner.

$\mathrm{T}=$ total kunjungan wisatawan ke Hutan Wisata Taman Eden 100 yang dicari selama setahun.

Berdasarkan rata - rata biaya perjalanan pergi pulang (Travel Cost) dari jumlah wisatawan dan jumlah kunjungan ke hutan wisata Taman Eden 100 selama 2018 yang berjumlah 2.909 orang, diperoleh rata rata total biaya perjalanan 50 responden sebesar 400.200, maka manfaat total nilai penggunaan langsung (Use Value) diperoleh hasil sebagai berikut :

$\mathrm{TTC}=\sum_{i=1}^{50} A T C i\left[\begin{array}{c}n i \\ N\end{array}\right] T=400.200 \times \frac{50}{50} \mathrm{x}$ 2909 orang adalah sebesar Rp 1.164.181.800.

Dari hasil perhitungan di daerah penelitian, dapat disimpulkan bahwa manfaat total nilai penggunaan langsung hutan wisata Taman Eden 100 sebagai objek wisata memiliki nilai yang sangat besar yaitu $\mathrm{Rp}$ 1.164.181.800. Nilai ini dapat juga dijadikan sebagai pedoman dalam mengelola dan melestarikan sumberdaya alam, sehingga fungsi dari ekosistem itu sendiri dapat terjaga dengan baik.

\subsubsection{Nilai ekonomi keberadaan hutan wisata Taman Eden 100 menggunakan wtp (willingness to pay)}

Nilai tanpa penggunaan (non use value) yang terdiri dari nilai keberadaan Hutan Wisata Taman Eden 100 yang diukur dengan metode valuasi kontingen (contingent valuation method, CVM). Dalam kesediaan membayar akan menggunakan pendekatan data sampel. Metode ini akan menghitung kesediaan untuk membayar (willingness to pay, WTP) per wisatawan per kunjungan. Tawaran mulai dari harga tiket masuk yang 
berlaku yaitu Rp 5.000 sampai dengan $\mathrm{Rp}$ 50.000 yang merupakan penawaran tertinggi. Hal ini berdasarkan dengan penelitian empirik yang dilakukan oleh Grandstaff and Dixon (1991:168) dalam Ketut Suja (2007), seperti persamaan berikut :

$$
\mathrm{TWTP}=\sum_{i=1}^{n} A W T P i\left[\begin{array}{c}
n i \\
N
\end{array}\right] T
$$

Dari Tabel 2 dapat disimpulkan bahwa kesediaan membayar akan keberadaan hutan Taman Eden 100 tertinggi yaitu sebesar Rp 45.000 dengan jumlah orang yang bersedia sebanyak 4 orang, dan nilai kesediaan membayar terendah yaitu sebesar Rp 8.000 dengan jumlah orang yang bersedia yaitu sebanyak 9 orang. Grafik kesediaan membayar pengunjung dapat terlihat pada Gambar 2.
Tabel 2. Nominal per kunjungan untuk kesediaan membayar

\begin{tabular}{ccc}
\hline $\begin{array}{c}\text { Nominal } \\
\text { (Dalam Rp) }\end{array}$ & Frekuensi & Persen \\
\hline 8.000 & 9 & 18 \\
14.000 & 12 & 24 \\
20.000 & 16 & 32 \\
26.000 & 3 & 6 \\
32.000 & 2 & 4 \\
38.000 & 4 & 8 \\
45.000 & 4 & 8 \\
\hline Total & $\mathbf{5 0}$ & $\mathbf{1 0 0}$ \\
\hline
\end{tabular}

Sumber : Diolah dari data Primer

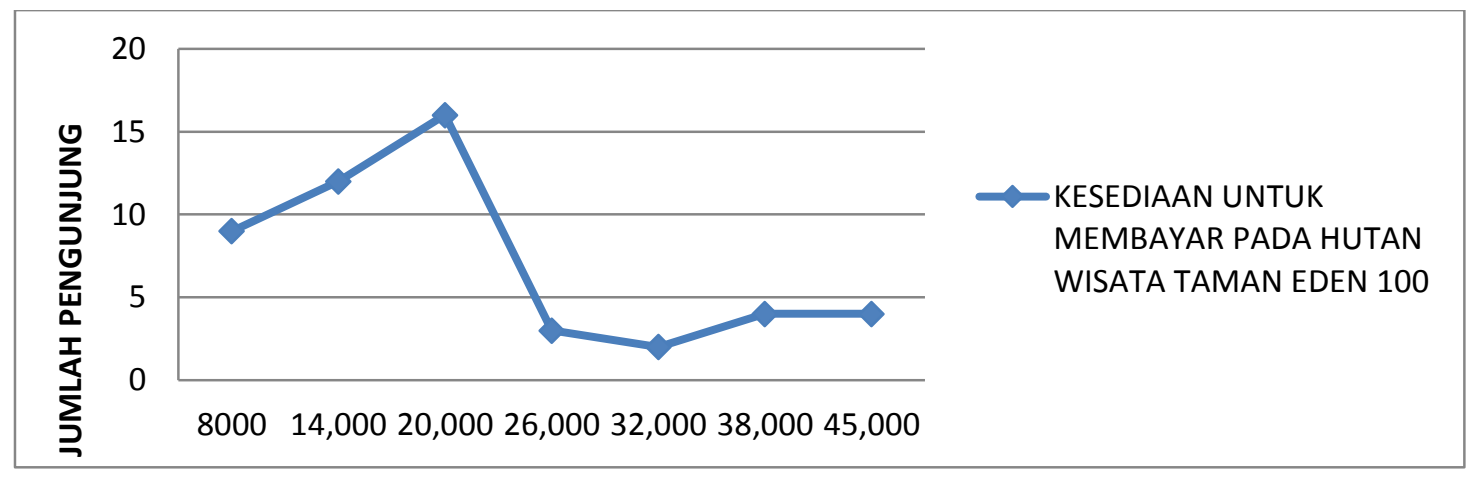

Gambar 2

Kesediaan Untuk Membayar (WTP) pada Hutan Taman Eden 100 Sumber : Diolah dari data Primer

Pada Gambar 2 menunjukkan bahwa kurva permintaan bersifat linear, artinya dimana semakin tinggi tawaran kesediaan untuk membayar masuk ke dalam hutan Taman Eden 100 sebagai salah satu objek wisata, maka semakin sedikit jumlah wisatawan yang mengunjunginya, dan semakin kecil tawaran kesediaan untuk membayar maka semakin banyak jumlah wisatawan yang datang ke lokasi hutan Taman Eden 100.

Berdasarkan jumlah kunjungan tahun 2018 serta rata rata kesediaan untuk membayar per kunjungan selama setahun (Tabel 2) sebesar Rp 20.680 maka diperoleh total nilai tanpa penggunaan (non use value, NUV) sebagai berikut :

$\mathrm{TTC}=\sum_{i=1}^{50} A T C i\left[\begin{array}{c}n i \\ N\end{array}\right] T=20.680 \quad \mathrm{x} \frac{50}{50} \mathrm{x}$ 2909 orang $=\operatorname{Rp} \quad 60.158 .120$

Dari hasil penelitian, maka dapat disimpulkan, bahwa nilai ekonomi hutan Taman Eden 100 sebagai nilai keberadaan untuk jasa jasa lingkungan atau sumberdaya sebesar Rp 60.158.120. 


\subsubsection{Nilai Ekonomi Penyerapan Karbon Hutan Wisata Taman Eden 100}

Perhitungan pendugaan biomassa dan perhitungan stok karbon hutan wisata Taman Eden 100 menggunakan model perhitungan allometrik non destruktif, dimana perhitungan dilakukan tanpa menebang pohon ataupun memotong bagian batang pohon. Perhitungan pendugaan biomassa ini menggunakan penelitian persamaan allometrik yang sebelumnya telah dilakukan yang jenis hutannya sama dengan hutan Taman Eden 100, oleh Thojib et al., (2002) yang lokasi nya di hutan lahan kering sekunder di Provinsi Jambi Pedoman Penggunaan Model Alometrik (2013), seperti persamaan berikut:

$$
\mathrm{BPA}=0,0639 \mathrm{D}^{2 / 3903}
$$

Keterangan:

BPA = Biomassa Permukaan Atas

$\mathrm{D} \quad=$ diameter pohon

Setelah menghitung Biomassa pohon bagian atas, maka selanjutnya dilakukan perhitungan stok karbon, dengan mengalikan hasil biomassa permukaan atas dengan fraksi karbon $(0,48)$. Setelah itu stok karbon dikonversi ke $\mathrm{CO}_{2}$ ekuivalen dengan menggunakan perbandingan massa atom relatif $\mathrm{C}$ (12) dengan massa molekul relatif $\mathrm{CO}_{2}$ (44).Hasil dari pengukuran 5 plot pada sampling di daerah penelitian dapat dilihat pada Tabel 3.

Tabel 3. Perhitungan Stok Karbon

\begin{tabular}{ccccc}
\hline $\begin{array}{c}\text { Nomor } \\
\text { Plot }\end{array}$ & $\begin{array}{c}\text { Biomassa } \\
\text { (ton/ha) }\end{array}$ & $\begin{array}{c}\text { Fraksi } \\
\text { Karbon }\end{array}$ & $\begin{array}{c}\text { Stok Karbon (ton } \\
\text { C/ha) }\end{array}$ & $\mathrm{CO}_{2}$ ekivalen (ton/ha) \\
\hline 1 & 3.871 & 0,47 & 1.820 & 6.673 \\
\hline 2 & 4.133 & 0,47 & 1.943 & 7.124 \\
\hline 3 & 5.714 & 0,47 & 2.685 & 9.845 \\
\hline 4 & 5.243 & 0,47 & 2.464 & 9.035 \\
\hline 5 & 6.129 & 0,47 & 2.881 & 10.564 \\
\hline Total & 25.090 & & 11.793 & 23.643 \\
\hline
\end{tabular}

Sumber : Diolah dari data Primer

Dari hasil penelitian di lima plot dengan masing-masing luas plot $(20 \mathrm{~m} \mathrm{x}$ $20 \mathrm{~m}$ ), maka estimasi atau dugaan stok penyerapan cadangan karbon pada Hutan Wisata Taman Eden adalah sebesar 129.723 ton $\mathrm{C} / \mathrm{Ha}$ dan stok $\mathrm{CO}_{2}(\mathrm{eq})$ sebesar 475.651 ton $\mathrm{C} / \mathrm{Ha}$. Berdasarkan harga karbon mengikuti standart World Bank US \$ 10 / per ton tersimpan atau bila diasumsikan nilai tukar US \$1 sebesar Rp 14.000, mengacu pada hal tersebut maka nilai ekonomi potensi karbon tersimpan dapat diketahui yaitu sebesar Rp 18.161.220.000 per tahun. Nilai penyerapan karbon ini merupakan nilai manfaat yang bisa diberikan masyarakat dunia atas kualitas ekosistem Hutan Wisata Taman Eden 100 sebagai kawasan hutan yang mempu berfungsi sebagai penyerap emisi $\mathrm{CO}_{2}$.

\subsubsection{Nilai Ekonomi Total ( Total Economic Value, TEV)}

Nilai ekonomi total hutan wisata Taman Eden 100 diperoleh dengan menjumlahkan seluruh nilai ekonomi jasa lingkungan. Dimana use value (nilai penggunaan langsung) berupa pendugaan nilai ekonomi pohon sebesar Rp 7.822.633.800 dan nilai ekonomi hasil hutan non kayu (buah-buahan) sebesar Rp 25.500.000, nilai penggunaan tak langsung berupa ekowisata menggunakan travel cost sebesar Rp 1.164.181.800, sedangkan nilai non guna (NUV) terdiri dari nilai keberadaan menggunakan metode Contingent Valuation Method sebesar Rp 60.158.120 dan nilai penyerapan karbon yang termasukk nilai warisan sebesar $\mathrm{Rp}$ 10.922.239.920, maka 
total nilai ekonomi Hutan Wisata Taman Eden adalah :

$$
\begin{gathered}
\mathrm{TEV} \quad=\mathrm{UV}+\mathrm{NUV} \\
=(\mathrm{DUV}+\mathrm{IUV})+(\mathrm{EV}+\mathrm{BV}) \\
=(\operatorname{Rp} 7.822 .633 .800+25.500 .000+\mathrm{Rp} 1.164 .181 .800)+ \\
(\operatorname{Rp~60.158.120+Rp~18.161.220.000)~} \\
=\operatorname{Rp} 9.012 .315 .600+18.221 .378 .120 \\
=\operatorname{Rp~27.233.693.720~}
\end{gathered}
$$

Maka dapat disimpulkan, bahwa Nilai Ekonomi Total (total economic value, TEV) Hutan Wisata Taman Eden 100 sebagai salah satu objek wisata sebesar Rp 10.922.239.920, ini dapat dikatakan bahwa nilai ini merupakan suatu nilai ekonomi yang dimiliki oleh Hutan Wisata Taman Eden 100 sebagai penyedia jasa lingkungan.

\subsection{Kendala dan Tantangan}

Kendala utama yang dihadapi dalam pengelolaan dan pelestarian jasa lingkungan adala nilai jasa ekosistem hutan sulit untuk diuangkan karena tidak memiliki nilai pasar. Berbeda dengan manfaat hutan yang tampak nyata seperti kayu, rotan, ikan, dan hewan buruan yang dapat dijual dan dikonsumsi, sehingga jasa lingkungan sedikit yang tampak nyata karena bersifat ekesternalitas. Bagi pengunjung dan masyarakat sekitar, pemanfaatan hutan wisata Taman Eden 100 hanya soal keindahannya saja, selain itu masyarakat juga pada umumnya hanya mengetahui cara mengambil atau memanfaatkan hasil-hasil hutan berdasarkan pengetahuan mereka sendiri yang telah diwariskan secara turun-temurun dari leluhur mereka, tanpa mengetahui cara yang tepat untuk menjaga kelestarian dan eksistensi hutan wisata Taman Eden 100. Hal inilah yang menyebabkan rendahnya kesediaan membayar lebih masyarakat dan pengunjung dalam pengelolaan dan pelestarian hutan wisata Taman Eden 100. Padahal, menjaga kelestarian hutan wisata Taman Eden dapat memberikan manfaat berkelanjutan seperti jasa lingkungan hidrologis, penyerapan karbon, produksi kayu dan tempat keanekaragaman hayati.

Faktor lain yang menjadi kendala pengelola adalah kurang adanya kebijakan yang mendukung. Faktor kebijakan ini sangat penting karena dapat memberikan insentif pada pemanfaatan jasa lingkungan hutan.
Sebagai contoh, pemanfaatan karbon hutan mungkin dapat dilaksanakan jika pemerintah memberlakukan peraturan perdagangan karbon dengan mekanisme yang dapat dilakukan di tingkat lokal dan melibatkan para pihak seperti perusahaan lokal dan masyarakat lokal. Tidak hanya itu, adanya sosialisasi akan jasa lingkungan dan pemanfaatannya kepada masyarakat juga sangat dibutuhkan

Peran dan perhatian dari pemerintah juga sangat dibutuhkan oleh pihak pengelola dalam mendukung pengelolaan dan pelestarian kawasan hutan wisata Taman Eden 100 dalam menyediakan jasa lingkungan yang berkelanjutan.

\section{SIMPULAN DAN SARAN}

\subsection{Simpulan}

1. Hutan Taman Eden 100 menyediakan jasa lingkungan baik berupa nilai guna maupun non guna. Jasa lingkungan yang disediakan oleh hutan Taman Eden 100 berupa jasa lingkungan produksi kayu dan non kayu, jasa lingkungan penyedia wisata alam, jasa lingkungan keberadaan dan jasa lingkungan warisan berupa penyerapan karbon.

2. Valuasi ekonomi jasa lingkungan hutan Taman Eden 100 diperoleh sebesar Rp 27.233.693.720. Nilai ini diperoleh dari penjumlahan seluruh nilai ekonomi, baik nilai ekonomi guna maupun non guna. Nilai ekonomi penggunaan (use value) terdiri dari nilai ekonomi langsung berupa produksi kayu dan non kayu yang berjumlah $\mathrm{Rp}$ 7.848.133.800,sedangkan nilai guna tidak langsung berupa ekowisata yang diukur dengan travel cost sebesar Rp 1.164.181.800 . Nilai ekonomi non guna (non use value) terdiri dari nilai keberadaan ekosistem hutan Taman Eden 100 yang diukur dengan CVM sebesar Rp 60.158.120, sedangkan nilai non guna warisan berupa penyerapan karbon yang diukur dengan metode allometrik sebesar Rp 18.161.220.000.

3. Kendala dan tantangan yang dihadapi oleh pengelola adalah masyarakat sekitar dan pengunjung kurang mengetahui nilai-nilai 
penting dan arti hutan yang sebenarnya bagi kehidupan mereka. Bagi pengunjung dan masyarakat sekitar, pemanfaatan hutan wisata Taman Eden 100 hanya soal keindahannya saja, selain itu masyarakat juga pada umumnya hanya mengetahui cara mengambil atau memanfaatkan hasilhasil hutan berdasarkan pengetahuan mereka sendiri yang telah diwariskan secara turun-temurun dari leluhur mereka, tanpa mengetahui cara yang tepat untuk menjaga kelestarian dan eksistensi hutan wisata Taman Eden 100.

\subsection{Saran}

1. Perlunya sosialisasi ke masyarakat sekitar pentingnya dalam menjaga kelestarian hutan. Selain itu, adanya pendekatan ke masyarakat dan pengunjung akan jasa lingkungan yang tersedia di hutan wisata Taman Eden 100.

2. Perlu adanya perbaikan manajemen pengelola hutan Taman Eden 100 dalam pembukuan data-data, nama jenis-jenis pohon, data biaya yang dikeluarkan dalam menjaga kelestarian lingkungan serta adanya evaluasi mengenai harga tiket masuk yang terbilang sangat murah.

3. Perlu adanya peningkatan kepedulian dari pemerintah untuk membantu kelestarian hutan Taman Eden 100, serta peningkatan kerjasama dengan pihak swasta dan partisipasi dalam menjaga kelestarian lingkungan

\section{DAFTAR PUSTAKA}

Brown, S. (1997). Estimating Biomass And Biomass Change Of Tropical Forest. A primer FAO Forestry paper, 134.

Heriyanto, N dan Endro S. 2016. Peran Biomasa Mangrove Dalam Menyimpan Karbon Di Kubu Raya, Kalimantan Barat. Vol 13 : 2. Jurnal Analisis Kebijakan. Bogor: Pusat Penelitian dan Pengembangan Hutan.

Husch B, Beers TW and Kershaw JA. 2003. Forest Mensuration, Fourth Edition. John Wiley \& Sons, Inc.

Menteri Lingkungan Hidup Dan Kehutanan Republik Indonesia Nomor: P.64/Menlhk/Setjen/Kum.1/12/2017
Tentang : "Penetapan Harga

Patokan Hasil Hutan Untuk

Perhitungan Provisi Sumber Daya

Hutan Dan Ganti Rugi Tegakan”.

Suja, I Ketut M. A. (2007)."Nilai Ekonomi Kawasan Wisata Alam Danau Buyan-Tamblingan Sebagai Objek Wisata Di Bali Suatu Kajian Ekonomi Lingkungan" (tesis). Denpasar : Universitas Udayana.

Suwarno, Eno. 2013. Analisis Potensi dan Nilai Ekonomi Karbon Hutan Tanaman Industri Ecalyptus Pellita. Prosiding Seminar Nasional Konservasi dan Proteksi Lingkungan. Program Pascasarjana Universitas Riau Program Studi Ilmu Lingkungan. https://researchgate.net/publication/31 9629113. [Diakses pada tanggal 1 Oktober 2018].

Munasinghe, M. 1993. Environmental Economics and Sustainable Development. World Bank Environment Paper Number 3. The World Bank. Washington D.C.

Tampubolon, R. 2008. Studi Jasa Lingkungan Di Kawasan Danau Toba. ITTO. Japan. (http://www.forda-mof.org). [Diakses pada tanggal 23 September 2018].

Thojib, A., Supriyadi, Hardiwinoto, S., dan Okimori. 2002. Estimation Formulas Of Aboveground Biomass in Several Land-Use Systems in Tropical Ecosystems Of Jambi. Sumatera Selatan.

Wibowo, A., Ginoga, K., Nurfatriani, F., Indartik., Dwiprabowo, H., Ekawati, S., Krisnawati, H., Siregar C, A. 2010. REDD \& forest GOVERNANCE. Pusat Penelitian Sosial Ekonomi dan Kebijakan Kehutanan. Kampus BALITBANG Kehutanan. Bogor.

Yastori, Chairul, Syamsuardi. 2016. Keanekaragaman Jenis Tumbuhan Dan Pendugaan Cadangan Karbon Di Atas Permukaan Tanah Di Kawasan Hutan Bukit Barisan Bagian Barat Kota Padang. Vol (2): 65-73. Jurnal Metamorfosa III. 